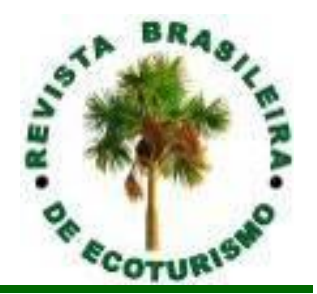

\title{
Uso de indicadores de sustentabilidade no contexto da atividade turística
}

\author{
Use of sustainability indicators in the context of the tourism activity
}

\author{
Suélen Daianne de Oliveira
}

\begin{abstract}
RESUMO: A atividade turística contribui para o desenvolvimento econômico, mas pode causar diversos impactos ao meio natural e a comunidade receptora. Acreditase que é possível haver o desenvolvimento do turismo em ambientes naturais, no entanto, é necessário um estudo das fragilidades do local e um planejamento adequado, de maneira que possibilite a exploração da atividade e a conservação do ambiente para as futuras gerações. Sendo assim, os indicadores de sustentabilidade podem ser vistos como instrumentos que possibilitam o monitoramento do turismo sustentável em todas as suas dimensões: ambiental, sociocultural, econômica e político-institucional. Eles podem ser utilizados pelos gestores na identificação dos problemas e servem como base para auxiliar nas tomadas de decisões. Diante disso, o presente trabalho, de caráter bibliográfico, tem como objetivo discutir os conceitos de turismo sustentável, analisar os indicadores de sustentabilidade bem como os modelos utilizados, visando a sua compreensão e aplicação ao contexto da atividade turística.
\end{abstract}

PALAVRAS CHAVE: Turismo Sustentável; Indicadores de Sustentabilidade; Atividade Turística

ABSTRACT: Tourism activity contributes to economic development, but it can cause diverse impacts to the natural environment and the receiving community. It is believed that it is possible to develop tourism in natural environments, however, it is necessary to study the fragilities of the place and adequate planning, in a way that allows exploration of the activity and conservation of the environment for future generations. Therefore, sustainability indicators can be seen as instruments that enable the monitoring of sustainable tourism in all its dimensions: environmental, socio-cultural, economic and political-institutional. They can be used by managers to identify problems and serve as a basis to assist in decision making. Therefore, the present bibliographic work aims to discuss the concepts of sustainable tourism, analyze sustainability indicators as well as the models used, aiming to understand and apply to the context of tourism.

KEYWORDS: Sustainable Tourism; Indicators of Sustainability; Tourist Activity. 


\section{Introdução}

Ações antrópicas têm causado intensos impactos ao meio natural ao longo dos anos. A revolução industrial agilizou substancialmente os processos industriais e consequentemente acelerou a urbanização, situações que refletiram em maiores degradações ao meio ambiente. Santos (2006, p. 118), relaciona às conquistas tecnológicas e a busca incessante pelo lucro aos impactos ocorridos a natureza:

Em sua versão contemporânea, a tecnologia se pôs ao serviço de uma produção à escala planetária, onde nem os limites dos Estados, nem os dos recursos, nem os dos direitos humanos são levados em conta. Nada é levado em conta, exceto a busca desenfreada do lucro, onde quer que se encontrem os elementos capazes de permitilo (SANTOS, 2006, p. 118).

Por conta de um cenário preocupante de degradação ambiental em todo o mundo, despertou na sociedade a preocupação com a escassez dos recursos naturais e com o futuro das próximas gerações. Entretanto, o consumo tem aumentado cada vez mais e com isso surgem as discussões sobre a sustentabilidade. Tem se buscado constantemente alcançar a sustentabilidade nas mais variadas atividades, e entre elas o turismo.

A atividade turística contribui para o desenvolvimento econômico de diversas regiões, mas também pode causar diversos impactos, entre eles: ambientais, sociais e culturais. Podemos entender esses impactos como o "conjunto de intervenções e modificações decorrentes do desenvolvimento turísticos nos núcleos receptores" (KÖRÖSSY, 2008, p. 59).

Cada vez mais o visitante tem buscado ambientes naturais para passar as férias. Ao ambiente natural, o turismo pode causar impactos diretos ao solo, à fauna, à flora, aos recursos hídricos, ao ar, à geologia e às paisagens (REICHERT; LANZER, 2015). Destaca-se os impactos relativos ao aumento de consumo de combustíveis, eletricidade, alimentos e bebidas, que geram resíduos e emissões de poluentes nas localidades turísticas (PIRES, 2010).

Apesar dos impactos descritos anteriormente, a atividade turística realizada no ambiente natural não se resume em degradação ambiental. A criação de planos de conservação e preservação de áreas naturais, valorização do convívio com a natureza e investimentos em medidas preservacionistas são alguns dos efeitos que turismo pode trazer a localidade. Além da preservação ao meio natural também podemos elencar outros benefícios como aumento da renda e interação cultural (RUSCHMANN, 2012).

Diante de tantas alterações que a atividade turística pode acarretar, o ideal é que os impactos positivos sejam maximizados e, por outro lado, os negativos sejam minimizados ou suprimidos.

Com relação aos impactos ao meio ambiente, o próprio trade turístico deve ser o maior interessado em adotar medidas de planejamento e proteção, afinal, se o destino perder a atratividade os empreendedores turísticos podem sofrer prejuízos. Também é necessário pensar em conservar o atrativo natural para as futuras gerações, isto é, desenvolver o turismo de maneira sustentável. 
O conceito de turismo sustentável procede do conceito de desenvolvimento sustentável (KÖRÖSSY, 2008). Araújo (2009) menciona que as discussões sobre o desenvolvimento sustentável iniciaram durante a reunião de Estocolmo, em 1972. No entanto, foi popularizada na década de 1980 com o movimento ambientalista, e na década de 1990 o meio acadêmico ligado aos estudos do turismo também se envolveu com as discussões sobre o conceito.

A Organização Mundial do Turismo (OMT) tem a seguinte definição sobre turismo sustentável:

O desenvolvimento do turismo sustentável atende às necessidades dos turistas de hoje e das regiões receptoras, ao mesmo tempo em que protege e amplia as oportunidades para o futuro. É visto como um condutor ao gerenciamento de todos os recursos, de tal forma que as necessidades econômicas, sociais e estéticas possam ser satisfeitas sem desprezar a manutenção da integridade cultural, dos processos ecológicos essenciais, da diversidade biológica e dos sistemas que garantem a vida (OMT, 2003, p. 24).

Por muito tempo imaginou-se que a atividade turística seria uma "indústria limpa", porém, percebeu-se que ela pode causar impactos ao meio ambiente principalmente nos locais onde o turismo representa a principal atividade econômica. Dessa forma, a Organização Mundial do Turismo - OMT (2003) identificou a necessidade de adotar a abordagem sustentável para o turismo e aplicar os princípios de desenvolvimento sustentável aos seus estudos de planejamento e desenvolvimento turísticos.

Preocupados em promover o turismo responsável e sustentável, a OMT elaborou um documento chamado Código Mundial de Ética do Turismo após ampla consulta e contribuições de setores privados, ONG's e organizações de trabalhadores em turismo, com base em documentos como a Declaração dos Direitos do Homem, a Convenção de Chicago, a Declaração de Manilha, a Declaração do Rio, a Convenção sobre a Diversidade Biológica e a Declaração de Estocolmo. O Código é composto de dez artigos direcionados a todos os setores ligados ao turismo com o intuito de "minimizar os impactos negativos que o turismo gera no meio ambiente natural e na herança cultural de muitas localidades receptoras. $E$, ainda, potencializar os benefícios, de modo a salvaguardar o futuro da atividade" (BRASIL, 2007, p. 115).

Diversas entidades internacionais começaram a realizar iniciativas com o intuito de promover o turismo sustentável. O World Wildlife Fund-WWF-Brasil, organização não-governamental nacional que integra a Rede WWF, dedica-se à proteção do meio ambiente e tem buscado trabalhar com o turismo onde há ameaças à conservação da natureza e à justiça social em parceria com órgãos públicos, privados e comunidades locais, para que o turismo no Brasil projete a sustentabilidade sob os enfoques econômico, social e ambiental. Um dos locais que a instituição vem atuando é no estado do Amazonas ${ }^{1}$.

O setor público vislumbra o turismo como uma atividade geradora de renda, capaz de gerar empregos e movimentar economias estagnadas. Contudo, para garantir que o turismo continue promovendo esses benefícios é necessário assegurar que os causadores das viagens como os patrimônios naturais, culturais e 
históricos se mantenham em circunstâncias capazes de continuar desenvolvendo a atividade turística (SALVATI, 2004).

É necessária uma reflexão para o desenvolvimento da atividade turística, além do simples crescimento econômico. O turismo é capaz de gerar acentuados benefícios econômicos para as comunidades, porém, pode provocar diversos impactos, principalmente do ponto de vista ecológico. Sendo assim, dependendo da área a ser desenvolvida a atividade turística e do comportamento dos turistas, 0 turismo pode gerar sérios níveis de degradação ao ambiente natural que não compensam o retorno financeiro. Da mesma forma, entende-se que a exploração turística deve realizada se for viável tanto ambientalmente como socioeconomicamente.

Além dos benefícios econômicos, o turismo também é importante para o desenvolvimento sociocultural da localidade. A questão social compreende aspectos relacionados à qualidade de vida da população. Já a questão cultural abrange a troca de experiências entre os diferentes povos e fatores de preservação da cultura local, evitando, assim, a aculturação (STEFANI; OLIVEIRA, 2015).

Nesse contexto diversos destinos turísticos em várias partes do mundo estão empenhados em alcançar o turismo sustentável (KÖRÖSSY, 2008), entretanto, no Brasil ainda existem poucas iniciativas. O município de Brotas é um exemplo em que o poder público, privado e comunidade buscam alternativas para o planejamento de um turismo sustentável, inclusive realizando fóruns para a discussão de soluções para o município (BROTAS, 2018)².

O município de Bonito-MS é um destino que tem buscado promover algumas ações sustentáveis, como um rigoroso controle de turistas. Para obter um efetivo controle de visitantes nos atrativos, a maioria ligados à natureza, foi instituído o Voucher Único, como instrumento de ordenamento da atividade turística que contribuiu para induzir a um modelo de gestão baseado na constituição de uma rede de cooperação voltada a exploração sustentável dos recursos turísticos do município, envolvendo o poder público e o trade turístico (VIEIRA, 2003).

Sendo assim, o presente trabalho, tem como objetivo discutir os conceitos de turismo sustentável, analisar os indicadores de sustentabilidade bem como os modelos utilizados, visando a sua compreensão e aplicação ao contexto da atividade turística.

\section{Material e Métodos}

O presente estudo, utilizou-se como procedimento a pesquisa bibliográfica. Gil (1994) afirma que a pesquisa bibliográfica possibilita alcançar uma gama de informações dispersas em inúmeras publicações que auxiliam na construção ou na melhor definição do conceito que envolve o objeto de estudo proposto.

Nesse sentido, a pesquisa baseou-se em estudos disponibilizados em livros, artigos científicos, dissertações, site oficiais, entre outros. Desta forma, possibilitou o levantamento de informações sobre o tema pesquisado e a observação dos diferentes modelos de indicadores de sustentabilidade. 


\title{
Resultados e Discussão
}

\section{O turismo e a sustentabilidade}

De acordo com Körössy (2008) é importante diferenciar "turismo sustentável" de "sustentabilidade do turismo". Turismo sustentável trata-se da propagação da atividade turística utilizando o tripé da sustentabilidade. Por outro lado, a sustentabilidade do turismo refere-se a assegurar a realização da atividade mesmo que não seja necessariamente de maneira sustentável, ou seja, sem a preocupação de proteger o meio natural ou a justiça social, buscando apenas manter a atividade em funcionamento.

Também não se deve confundir turismo sustentável com os mais diversos tipos de turismo, tais como: ecoturismo, turismo rural, turismo ecológico etc. Se na prática de alguma dessas atividades não houver a proteção ao meio ambiente, o crescimento econômico do PIB de uma região e a busca pela justiça social da comunidade, não se pode afirmar que ela seja sustentável (KÖRÖSSY, 2008).

Existem duas interpretações distintas sobre a aplicação do turismo sustentável. Rodrigues (1997), por exemplo, considera que a atividade turística é inconciliável com o desenvolvimento sustentável, para ela "esta atividade produz territórios, da mesma forma que todas as demais atividades do modo industrial de produzir mercadorias e na sua essência é insustentável, pois temos de levar em conta que toda produção é ao mesmo tempo destruição (RODRIGUES, 1997, p. 42)". Já a Organização Mundial do Turismo - OMT, não só acredita que o turismo sustentável é possível, como também afirma que é aplicável a todas as formas de turismo:

\begin{abstract}
As diretrizes para o desenvolvimento do turismo sustentável e as práticas de gestão ambiental são aplicáveis a todas as formas de turismo em todos os tipos de destinos, incluindo o turismo de massa e seus diversos segmentos. Os princípios de sustentabilidade se referem aos aspectos ambientais, econômicos e socioculturais, devendo estabelecer um equilíbrio adequado entre as três dimensões para garantir sua sustentabilidade no longo prazo (WTO apud ZUCARATO; SANSOLO, 2006, p. 04).
\end{abstract}

A OMT ressalta a proteção ao meio ambiente e esclarece que o princípio básico extremamente importante para o desenvolvimento da atividade turística é não exceder os níveis de capacidade de carga dos locais. Para conquistar um turismo sustentável são necessários o apoio, a gestão e o comprometimento dos grupos envolvidos: setor público, setor privado, ONG's e os próprios turistas (OMT, 2003).

Para o Ministério do Turismo "o conceito de sustentabilidade deve ser entendido como princípio fundamental na reformulação do planejamento turístico nacional. Face à sua relevância como elemento orientador do modelo de desenvolvimento turístico desejado" (BRASIL, 2007, p. 15) e as relações entre turismo e sustentabilidade devem abordar os princípios: ambientais, econômicos, socioculturais e políticos-institucionais.

Beni (1999, p. 12) destaca que "a política global de sustentabilidade, em que a conservação do meio ambiente está intimamente relacionada com a eficiência econômica e a justiça social, ganhou ampla aceitação". Com isso, iniciaram os esforços para associar a proteção ao ambiente natural e o desenvolvimento da 
atividade turística. Em tempo, o autor afirma que com um bom planejamento e gestão, o turismo, o desenvolvimento regional e a proteção do ambiente podem evoluir paralelamente.

Para alcançar o equilíbrio almejado entre as ações humanas, o desenvolvimento e a proteção ambiental é necessária uma divisão de responsabilidades com relação ao consumo e ao comportamento referente aos recursos naturais (BENI, 2003). Beni (2003) também esclarece os aspectos que envolvem o turismo sustentável:

[...] compreensão dos impactos turísticos; distribuição justa de custos e benefícios; geração de empregos locais diretos e indiretos; fomento de negócios lucrativos; injeção de capital com consequente diversificação da economia local; interação com todos os setores e segmentos da sociedade; desenvolvimento estratégico e logístico de modais de transporte; encorajamento ao uso produtivo de terras tidas como marginais (turismo no espaço rural); subvenções para os custos de conservação ambiental (BENI, 2003, p.14).

Por meio da relação entre turismo e desenvolvimento sustentável foram criados diversos documentos oficiais ao longo do tempo, entre eles a Agenda 21 para Viagens e Turismo elaborado pela OMT, World Travel and Tourism Council e o Earth Council. Este documento estabelece o seguinte:

Para os departamentos governamentais, as associações nacionais de turismo e organizações comerciais representativas, o objetivo principal é estabelecer sistemas e procedimentos para incorporar as considerações sobre o desenvolvimento sustentável ao centro do processo de tomada de decisão e identificar as ações necessárias à criação do turismo sustentável. Para as empresas, o objetivo principal é estabelecer sistemas e procedimentos para incorporar as questões do desenvolvimento sustentável, como parte da função gerencial central, e identificar as ações necessárias à criação do turismo sustentável (OMT, 2003, p. 25).

A agenda 21 para Viagens e Turismo estabelece algumas determinações para o desenvolvimento do turismo sustentável. Em áreas sensíveis ou de proteção, o documento recomenda a análise do impacto ambiental, ou em alguns casos, aconselha os gestores a serem contrários ao desenvolvimento da atividade turística (OMT, 2003).

Além deste, diversos outros guias e manuais foram lançados pela OMT nos quais são apresentados os conceitos, princípios e técnicas para o planejamento, desenvolvimento e gerenciamento do turismo, bem como os indicadores para a aplicação em destinos turísticos. 


\section{Sistemas de Indicadores de sustentabilidade}

Os indicadores de sustentabilidade são ferramentas que buscam mensurar a sustentabilidade e têm como objetivo quantificar informações simplificando-as para melhorar a comunicação e gestão (Van Bellen, 2006).

De acordo com Monjardino (2009), a importância dos indicadores resulta da interpretação e da sua utilização como instrumento de análise e diagnóstico. "Um indicador é, pois, algo que nos ajuda a perceber onde estamos, para onde vamos e a que distância nos encontramos de onde queremos estar" (MONJARDINO, 2009, p. 1370).

Nos estudos de Van Bellen (2004) três sistemas principais foram escolhidos por especialistas para avaliar a sustentabilidade, são eles: Ecological Footprint Method, traduzido como "Método da Pegada Ecológica", Dashboard of Sustainability, em português "Painel de Sustentabilidade" e Barometer of Sustainability, isto é, "Barômetro da Sustentabilidade". O quadro a seguir apresenta as características de cada um deles:

Quadro 1: Metodologias de avaliação da sustentabilidade.

Frame 1: Sustainability assessment methodologies.

\begin{tabular}{|l|l|}
\hline $\begin{array}{l}\text { Metodologia de avaliação da } \\
\text { sustentabilidade }\end{array}$ & \multicolumn{1}{c|}{ Características } \\
\hline Ecological Footprint Method & $\begin{array}{l}\text { Consiste em definir a área necessária para manter uma } \\
\text { determinada população ou sistema econômico indefinidamente" } \\
\text { (VAN BELLEN, 2004, p. 70). Essa técnica contribui para } \\
\text { conscientizar a população a respeito dos problemas ambientais. } \\
\text { O método é baseado na capacidade de carga, ou seja, o } \\
\text { tamanho da população que o sistema pode suportar por um } \\
\text { período indeterminado. }\end{array}$ \\
\hline Dashboard of Sustainability & $\begin{array}{l}\text { É representado graficamente como um painel com três } \\
\text { mostradores que buscam mensurar as performances } \\
\text { econômica, social e ambiental de um país, município, } \\
\text { empreendimento, etc. A apresentação tem o intuito de chamar a } \\
\text { atenção do público-alvo. O conceito refere-se ao índice } \\
\text { agregado dos indicadores dentro de cada um dos mostradores, } \\
\text { obtém-se o resultado final por meio dos cálculos desses índices. } \\
\text { Tem como diferencial ser um sistema flexível pois as dimensões } \\
\text { podem ser modificadas de acordo com as necessidades dos } \\
\text { usuários. }\end{array}$ \\
\hline $\begin{array}{l}\text { É uma ferramenta que apresenta os resultados através de } \\
\text { índices utilizando a combinação de indicadores sobre o bem- } \\
\text { estar social e da ecosfera. Tais índices usam a representação } \\
\text { gráfica para demonstrar os dados de uma maneira mais fácil, } \\
\text { caso necessário é possível destacar aspectos mais importantes. }\end{array}$ \\
\hline Barometer of Sustainability
\end{tabular}

Fonte: VAN BELLEN, 2004.

Source: VAN BELLEN, 2004.

Para o IBGE (2015), os indicadores de desenvolvimento sustentável são instrumentos essenciais para o acompanhamento e avaliação do progresso que se pretende atingir. O órgão publicou em 2002 uma série de indicadores nas dimensões ambiental, social, econômico e institucional com base nos dados adquiridos em pesquisas. Segundo o IBGE (2015) por meio dos indicadores é possível obter um panorama com informações importantes para o planejamento e formulação de políticas públicas para o desenvolvimento sustentável. 
A utilização de indicadores de sustentabilidade, entre outros objetivos, possibilita a avaliação de políticas e resultados, permitindo o acompanhamento, inclusive de melhorias de índices relacionados aos aspectos ambientais, se for o caso. No entanto, para haver mudanças nos modos de produção para um modelo mais sustentável são necessárias transformações nas políticas públicas e implementar os princípios da sustentabilidade em todos os setores, inclusive na atividade turística (TRENTIN; SANSOLO, 2006).

\section{Indicadores no contexto da atividade turística}

O setor do turismo vem crescendo de maneira expressiva, inclusive no Brasil ${ }^{3}$. Sendo assim, torna-se imprescindível gerenciar os impactos que atividade pode causar aos destinos. "Os indicadores são vistos como elementos que apoiam o monitoramento do turismo sustentável, tendo em vista todas as suas dimensões: ambiental, sociocultural, econômica e político-institucional” (BRASIL, 2007, p. 67).

"Indicadores são ferramentas utilizadas nos sistemas de gestão e nos planos de monitoria e avaliação para dimensionar as mudanças nos aspectos considerados mais importantes da sustentabilidade de uma região ou produto turístico" (BRASIL, 2007, p. 65). Através dos indicadores é possível identificar e avaliar o resultado das ações implementadas.

O uso de indicadores de sustentabilidade na atividade turística pode ajudar a identificar os problemas sociais e ambientais além de auxiliar na gestão e no desenvolvimento da atividade. Por meio dos indicadores é possível fazer um diagnóstico da situação atual bem como monitorar a atividade turística em determinado local. Também é possível definir metas e realizar o acompanhamento para verificar se elas estão sendo atingidas.

Monjardino (2009) alega que são poucos indicadores relacionados ao turismo e que isso é compreensível devido a problemática do desenvolvimento sustentável. O Turismo é um setor que dispõe de uma informação estatística de base particularmente fraca e, portanto, existe a necessidade de melhorar os mecanismos de controle do desenvolvimento desta atividade.

Stilwell (2011) afirma que existem indefinições com relação ao conceito de turismo sustentável e sobre a melhor metodologia a ser utilizada para a avaliação e monitoramento da atividade. Entretanto, sem indicadores para supervisionar o desempenho econômico, ambiental e social não há como a atividade turística atingir um desenvolvimento sustentável. Porém, apenas a utilização de indicadores não garante os resultados esperados, mas a presença de informação clara estimula a tomada de ações para a resolução dos problemas. Dessa forma, o autor declara ser importante a utilização dos indicadores pois eles podem contribuir, de maneira significativa, com a promoção da sustentabilidade.

Indicadores são capazes de refletir e medir, de maneira objetiva, os processos de desenvolvimento sob a égide da sustentabilidade. Portanto, trata-se de instrumentos práticos para a gestão e controle da atividade turística em determinada localidade. Porém, para o planejamento e desenvolvimento do turismo sustentável é fundamental a seleção e monitoramento frequente. Por meio do acompanhamento regular é possível observar as transformações da atividade turística com o passar do tempo em determinado local bem como visualizar e intensificar as metas estabelecidas (HANAI; ESPÍNDOLA, 2011). 
O uso dos indicadores pode culminar na adoção de medidas para antecipar e evitar situações indesejáveis (ou insustentáveis) nos destinos. Dessa forma, informações quantitativas e qualitativas são igualmente úteis. Em qualquer destino, os melhores indicadores são aqueles que respondem aos riscos e preocupações fundamentais sobre a sustentabilidade do turismo e fornecem informações que podem ajudar a minimizar os problemas e avaliar as respostas. Indicadores tipicamente respondem a questões relacionadas com os recursos naturais, econômicos e valores sociais e mais amplamente para questões de organização e gestão (ORGANIZACIÓN MUNDIAL DEL TURISMO, 2005).

Definir indicadores apropriados não é uma tarefa fácil "pois exige selecionar indicadores que representem os relevantes aspectos de viabilidade, sustentabilidade e desempenho do sistema e incorporá-los num procedimento sistemático, objetivo, compacto e compreensível' (HANAI; ESPÍNDOLA, 2011, p. 145), além disso, para alcançar os objetivos desejados, deve-se levar em conta o âmbito local.

Sendo assim, é importante que o desenvolvimento local atenda aos princípios da sustentabilidade, ou seja, que exista um equilíbrio entre as dimensões social, ambiental e econômica. Destarte, é necessário o envolvimento dos diversos atores sociais na gestão e execução das ações para o alcance do desenvolvimento sustentável. Dessa forma, o turismo representa uma atividade que pode causar impactos positivos e negativos na localidade que o desenvolve. Diante disso, destaca-se os sistemas de indicadores de sustentabilidade do turismo como instrumentos eficientes que propiciam a disponibilização de dados que podem contribuir na compreensão da atividade e, com isso, direcionar esforços para atingir o turismo sustentável (SANTOS, 2013).

A OMT produziu um conjunto de indicadores ambientais do turismo sustentável para diversos ambientes. Eles foram desenvolvidos para avaliar os impactos do turismo em uma área e podem ser utilizados pelos gestores para auxiliar na adoção de ações e nas tomadas de decisões. Dentre o conjunto, a instituição cita alguns como Indicadores Centrais do Turismo Sustentável, são eles: proteção do local, estresse, intensidade da utilização, impacto social, controle do desenvolvimento, gerenciamento dos resíduos, processo de planejamento, ecossistemas críticos, satisfação do consumidor, satisfação do local e contribuição turística para a economia local (OMT, 2003).

Trentin e Sansolo (2006) afirmam que a OMT percebeu a necessidade de estudos ao definir metodologias de indicadores ambientais de turismo sustentável visto que a atividade turística possui estreita relação com o meio ambiente. Por esse motivo, necessita de constante monitoramento, isto é, indicadores que demonstrem os impactos causados pela atividade.

É importante que os indicadores sejam desenvolvidos a partir de necessidades reais de informação e as bases podem ser dados que produzam resultados de fontes qualitativas ou quantitativas. Como exemplo de indicadores com bases quantitativas podemos citar: capacidade de suporte da infraestrutura turística e de apoio ao turismo; e ecoeficiência. E como exemplos de indicadores com bases qualitativas: capacidade de suporte social; e capacidade de suporte do turista (BRASIL, 2007, p. 67).

O turismo necessita do ambiente natural, sendo assim, o desenvolvimento da atividade depende da preservação do meio ambiente. No entanto, não se pode deixar de avaliar os impactos sociais, econômicos e culturais que a atividade pode 
causar. Dessa forma, entende-se que a realização da atividade turística deve ser baseada no tripé do desenvolvimento sustentável.

\section{Considerações finais}

A utilização consciente dos recursos naturais passou a ser uma necessidade por conta dos cenários preocupantes de degradação ambiental que ocorre em todo o mundo. Apesar das alterações que pode causar ao ambiente, a atividade turística pode ser vista como uma atividade menos predatória do ponto de vista de produção e consumo de recursos naturais. Se bem planejado e desenvolvido, o turismo pode contribuir para 0 alcance da sustentabilidade, tais como: auxiliando na conscientização e preservação dos recursos naturais; na conservação da cultura e valorização da comunidade local; e no desenvolvimento econômico da região.

Acredita-se que é possível haver o desenvolvimento do turismo em ambientes naturais, no entanto, é necessário um estudo das fragilidades do local e um planejamento adequado de maneira que possibilite a exploração da atividade e a conservação do ambiente para as futuras gerações.

Nesse contexto, mesmo diante da complexidade de selecionar os melhores indicadores, eles se mostram como ferramentas importantes, capazes de fornecer informações fundamentais para definir um diagnóstico e realizar o monitoramento de determinado local. Os resultados podem ser determinantes nas tomadas de decisões.

Sem dúvida, é um grande desafio encontrar maneiras de equilibrar aspectos sociais, ambientais e econômicos no desenvolvimento do turismo. Além de utilizar indicadores de sustentabilidade, os gestores devem envolver todos os atores locais como poder público, privado, comunidade e até mesmo os turistas, nesse processo que deve ser contínuo.

\section{Referências Bibliográficas}

ARAÚJO, L. M. Planejamento turístico regional: participação, parcerias e sustentabilidade. Maceió: UFAL, 2009.

BENI, M.C. Política e estratégia do desenvolvimento regional: planejamento integrado e sustentável do turismo. Revista Turismo em Análise, São Paulo, v. 10, n. 1, p. 7-17, maio 1999.

BENI, M.C. Como Certificar o Turismo Sustentável? Revista Turismo em Análise, São Paulo, v. 14, n. 2, p. 5-16, nov. 2003.

BRASIL (País). Instituto Brasileiro de Geografia e Estatística - IBGE. Indicadores de desenvolvimento sustentável. Rio de Janeiro: IBGE, 2015.

BRASIL (País). Ministério do Turismo. Glossário do Turismo. Disponível em: $<$ http://www.dadosefatos.turismo.gov.br/gloss\%C3\%A1rio-do-turismo/67outros/gloss\%C3\%A1rio-do-turismo/901-t.html>. Acesso em: 07 de agosto de 2018.

BRASIL (País). Ministério do Turismo. Turismo e Sustentabilidade: Programa de Regionalização do Turismo - Roteiros do Brasil. 1. ed. Brasília, 2007. 
BRASIL (País). Portal do governo federal. Faturamento das empresas de turismo cresce no primeiro trimestre. Disponível em: <http://www.brasil.gov.br/economia-eemprego/2017/06/faturamento-de-empresas-do-turismo-cresce-no-primeirotrimestre>. Acesso em: 07 de agosto de 2018.

BROTAS (Município). Brotas +20: Fórum discute atividade turística sustentável no município. Disponível em: <http://www.brotas.sp.gov.br/noticias.php?id=928>. Acesso em: 15 de agosto de 2018.

GIL, A.C. Métodos e técnicas de pesquisa social. São Paulo: Atlas, 1994.

HANAI, F. Y., ESPÍNDOLA, E. L. G. Indicadores de sustentabilidade: conceitos, tipologias e aplicação ao contexto do desenvolvimento turístico local. Revista de Gestão Social e Ambiental, São Paulo, v. 5, n. 3, p. 135-149, set./dez. 2011.

KÖRÖSSY, Nathália. Do turismo predatório ao turismo sustentável: uma revisão sobre a origem e a consolidação do discurso da sustentabilidade na atividade turística. Caderno Virtual de Turismo, Rio de Janeiro, v. 8, n. 2, p. 56-68, 2008.

MONJARDINO, I. C. C. Indicadores de Sustentabilidade do Turismo nos Açores: o papel das opiniões e da atitude dos residentes face ao Turismo na Região. In: 15을 Congresso da APDR-Redes e Desenvolvimento Regional, 2009, Cidade da Praia Cabo Verde, Actas... Cidade da Praia: APDR, 2009, p. 1366-1399.

ORGANIZAÇÃO MUNDIAL DE TURISMO (OMT). Guia de desenvolvimento do turismo sustentável. Tradução de Sandra Netz. Porto Alegre: Bookman, 2003.

ORGANIZACIÓN MUNDIAL DEL TURISMO. Indicadores de desarrollo sostenible para los destinos turísticos: guía práctica. Madrid: OMT, 2005. Disponível em: $<$ http://www.ucipfg.com/Repositorio/MGTS/MGTS14/MGTSV-07/tema2/OMT Indicadores de desarrollo de turismo sostenible para los destinos turisticos.pdf $>$ Acesso em: 12 de agosto de 2018.

PIRES, P.S. Turismo e meio ambiente: relação de interdependência. In: PHILIPPI JR., Arlindo; RUSCHMANN, Doris van de Meene. Gestão ambiental e sustentabilidade no turismo. Barueri: Manole, 2010.

REICHERT, L.; LANZER, R. M. O Desenvolvimento Turístico Sustentável em Lagoas Costeiras do Município de Osório, Rio Grande do Sul / Brasil: Características e especificidades destes recursos naturais. Revista TURyDES: Turismo y Desarrollo local, v. 8, n. 18, p.1-21, 2015.

RODRIGUES, A. B. Turismo e desenvolvimento local. São Paulo: Hucitec, 1997.

RUSCHMANN, D. Turismo e planejamento sustentável: a proteção do meio ambiente. 16 ${ }^{\underline{a}}$ ed. Campinas: Papirus, 2012.

SALVATI, S.C. (Org). Turismo Responsável - Manual para políticas públicas. Brasília: WWF Brasil, 2004.

SANTOS, J.G. Sistema de indicadores de sustentabilidade para o turismo: aplicação de uma abordagem participativa em Porto de Galinhas, PE. 2013. 219 f. Dissertação (Mestrado em Administração) - Universidade Federal de Pernambuco, Recife, 2013. Disponível em: <https://repositorio.ufpe.br/handle/123456789/10948>. Acesso em: 12 de agosto de 2018. 
SANTOS, M. A natureza do espaço: técnica e tempo, razão e emoção. 4. ed. São Paulo: EDUSP, 2006.

STEFANI, C.; OLIVEIRA, L.C.F.M. Compreendendo o turismo: um panorama da atividade. Curitiba: Intersaberes, 2015.

STILWELL, D. C. C. Indicadores de sustentabilidade aplicados ao contexto do desenvolvimento turístico português, 2011. 69 f. Dissertação (Mestrado em Ecologia e Gestão Ambiental) - Universidade de Lisboa, Lisboa, 2011. Disponível em:<http://repositorio.ul.pt/handle/10451/6512>. Acesso em: 25 de julho de 2018.

TRENTIN, F.; SANSOLO, D. G. Políticas públicas de turismo e indicadores de sustentabilidade ambiental: um estudo sobre Bonito - MS. Turismo - Visão e Ação, v. 8, n. 1, p. 61-74, jan. /abr. 2006.

VAN BELLEN, H.M. Desenvolvimento sustentável: uma descrição das principais ferramentas de avaliação. Ambiente e Sociedade, Campinas, v. 7, n. 1, p. 6787, jan./jun. 2004.

VAN BELLEN, H.M. Indicadores de Sustentabilidade: uma análise comparativa. 2. ed. Rio de Janeiro: FGV, 2006.

VIEIRA, J. F. L. Voucher único um modelo de gestão da atividade turística em Bonito, 2003, 137 f. Dissertação (Mestrado em Desenvolvimento Local) Universidade Católica Dom Bosco, Campo Grande, 2003. Disponível em: <https://site.ucdb.br/public/md-dissertacoes/7911-voucher-unico-um-modelo-degestao-da-atividade-turistica-em-bonito-ms.pdf>. Acesso em: 24 julho de 2018.

WWF. WWF-Brasil promove turismo sustentável no sul do Amazonas. Disponível em: <https://www.wwf.org.br/?52302>. Acesso em: 15 de agosto de 2018.

ZUCARATO, A.G.; SANSOLO, D.G. Uso de indicadores na pesquisa em turismo. IV SEMINTUR - Seminário de Pesquisa em Turismo do Mercosul, 4., 2006, Caxias do Sul. Anais... Caxias do Sul: UCS, 2006. Disponível em: .<https://www.ucs.br/ucs/tplSemMenus/eventos/seminarios semintur/semin tur 4/ar quivos 4 seminario/GT14-13.pdf >. Acesso em: 24 julho de 2018.

\section{Notas}

${ }^{1}$ Disponível em WWF (2018).

2 Disponível em Brotas (2018).

${ }^{3}$ Disponível em BRASIL - Portal do Governo Federal (2018).

Suélen Daianne de Oliveira: Universidade Estadual Paulista "Júlio de Mesquita Filho", Presidente Prudente, SP, Brasil.

E-mail: suelendaianne@hotmail.com

Link para o currículo Lattes: http://lattes.cnpq.br/7207178402077736

Data de submissão: 21/02/2019

Data de recebimento de correções: 18/12/2019

Data do aceite: 18/12/2019

Avaliado anonimamente 